\title{
DENSITY EFFECT ON MORPHOLOGICAL, MECHANICAL AND FRIABILITY PROPERTIES OF PHENOLIC FOAMS
}

\section{MOUGEL ${ }^{1,2}$, T. GARNIER ${ }^{2}$, N. SINTES-ZYDOWICZ ${ }^{1}$ and P. CASSAGNAU ${ }^{1}$}

${ }^{1}$ Univ Lyon

Université Claude Bernard Lyon 1

CNRS UMR 5223

Ingénierie des Matériaux Polymères

F-69622 Villeurbanne Cedex

France

e-mail: philippe.cassagnau@univ-lyon1.fr

${ }^{2}$ Robatel Industries

12 rue de Genève-CS 80011

69747 Genas Cedex

France

\begin{abstract}
This paper presents the effect of the phenolic foam density, in the range from

0.14 to $0.36 \mathrm{~g} . \mathrm{cm}^{-3}$, on the compression and flexural behaviours as well as on friability properties. The bulk and Young's modulus were determined from crushing and flexural tests respectively and compared to the Gibson and Ashby model. It is then observed that these experimental results are consistent with the model. Surprisingly, the plateau stress calculated from crushing tests does not follow the model of brittle foams defined by Gibson and Ashby but that of elastic foams. The maximum strain at break also contradicts the model but the
\end{abstract}

Keywords and phrases: phenolic foams, density, mechanical properties, morphology, friability. Received April 28, 2019

(ㄷ) 2019 Scientific Advances Publishers 
relation found in this work satisfies a more physically meaningful model, as this one indicates that the dense state has almost the same density as the densified foam. Furthermore, the results of the friability tests on phenolic foam were found to be highly dependent on density. In addition, the evolution of the microstructure versus density was also characterized by SEM and then processed with image analysis software. It was found that with increasing density, the average cell size decreases, cell size distribution narrows, and the cell density remains stable.

\section{Introduction}

Polymeric foams are extensively developed due to their great potential in several applications such as thermal and sound insulation, packaging, filter systems, structural elements and domestic elements [1]. The benefits given by the reduction of mass they offer compared to dense solid materials are numerous; they save energy in transport applications by lightening the structures and in insulation applications due to higher performances as well as they reduce the amount of raw materials used [1-4]. All of these reasons lead one to consider polymer foams as very attractive candidates for reducing the environmental impacts in the industrial field [1-4]. However, the commonly used polymeric foams, such as polyurethane and polystyrene foams, have high flammability and generate a great amount of smoke and harmful toxic gases while burning $[5,6]$.

With the increase in safety regulations, phenolic foams (PF) have been taken into consideration due to their excellent fire behaviour, i.e., high flame retardancy properties, the absence of dripping or/and low generation of toxic gases during combustion [7]. In addition, they have a low thermal conductivity $\left(0.022-0.040 \mathrm{~W} \cdot \mathrm{m}^{-1} \cdot \mathrm{K}^{-1}[4]\right)$, a high thermal stability over a large range of temperatures and they are cost-effective compared to other polymeric foams [8]. Nevertheless, these foams present two major drawbacks, i.e., high friability due to their brittleness and relatively low mechanical performances from the compressive and flexural point of views [8-11]. Despite this mechanical frailness, phenolic foams are generally used as insulating and structural materials when fire resistance is crucial for the required application. 
For shock absorption application as is the case for radioactive waste transportation, high-density foams are required $\left(d<0.1 \mathrm{~g} . \mathrm{cm}^{-3}\right)$, for which little information is reported in the literature [12]. Indeed, high mechanical performances can only be obtained with high foam density. Only a few studies have been reported on phenolic foams of densities higher than 0.1g.cm ${ }^{-3}$ [9, 13-16]. For instance, Del Saz-Orozco et al. investigated the effect of the reinforcement of phenolic foams in terms of friability, ageing, thermal and mechanical properties. Foam densities were equal to 0.16 and $0.12 \mathrm{~g} . \mathrm{cm}^{-3}$, and bio-based fillers such as cellulose fibres [13] and lignin particles or wood flour were used [14]. The compressive, shear and friability properties of phenolic foams reinforced with glass and aramid fibres, with a density comprised between 0.19 and $0.24 \mathrm{~g} . \mathrm{cm}^{-3}$, were also studied $[9,11]$. The compressive properties of the phenolic foam were enhanced whatever the reinforcement type. Nevertheless, glass fibres provided the most improvement. Aramid fibres were more efficient at reducing the friability while wood floor particles increased it.

The relationship between density and material properties is the key issue in structural applications for both opened-and closed-cell foams. In [3], Gibson and Ashby proposed several models that relate Young's modulus and the collapse stress to the relative density for various foam material behaviours such as elasticity, plasticity, or brittleness. However, St. Michel et al. [17] demonstrated that the Gibson and Ashby models were not quite suitable for modelling the compression behaviour of polyurethane foams with high density, i.e., between 0.33 and $0.85 \mathrm{~g} . \mathrm{cm}^{-3}$. Indeed, Gibson and Ashby's models are based on numerous assumptions: the cells are all similar and have a cubic geometry; the cells are stacked so that the vertical struts press against the middle of the struts of the neighbouring cell; the deformation is done by bending the struts which have a cubic section and are made of a homogeneous material. Moreover, while Gibson and Ashby's models assumed that the cells size did not influence the final mechanical properties, some authors have 
demonstrated opposite trends. For example, according to Chen et al. [18], closed-cell styrene-acrylonitrile foams with a density of $0.15 \mathrm{~g} . \mathrm{cm}^{-3}$ experience a decrease of both Young's modulus and compressive stress with cell size variation as well as with cell wall thickness variation. Xu et al. [19] demonstrated that $\mathrm{Mg}$ alloy brittle foams with smaller cell size possess better deformation stability and higher compressive strength by sharing the load with more numerous smaller cells. In opposition, Gaétane [20] studied polystyrene foam and found that on one hand Young's modulus, as well as the compressive strength, increased when the cell size increased for a solid fraction greater than $18 \%$; on the other hand, below this solid fraction compressive properties have almost no dependence on the cell size.

Moreover, the microstructure might be influenced by the amount of water contained in the phenolic resins [5]. It has been reported that increasing the water amount in the phenolic resin leads to the increase of the hole size in the cells walls [21] whereas no pinhole was observed with water amount below $7 \%$ wt. The foaming and curing temperatures might also play a role in the formation of the voids in the phenolic foams [5, 21]. Since the exothermic nature of the curing reaction, the temperature can greatly increase locally inducing the water vaporization. If the process temperature is too high, the vapour pressure can exceed the rupture strength of the cell walls leading to the cell burst and the formation of voids.

Nevertheless, to the best of our knowledge, no studies have been reported on the effect of density on the morphological, mechanical and friability properties of phenolic foams. Hence, this work aims at investigating the impact of relative density in the range 0.12 to $0.30 \mathrm{~g} . \mathrm{cm}^{-3}$ on the morphology, compressive behaviour, and friability properties. For that purpose, phenolic foams were investigated by scanning electron microscopy (SEM); the obtained images were analyzed in order to quantitatively determine morphological parameters such as the cells size, the cells size distribution or the cells density. In addition, 
the results of mechanical crushing measurements, such as bulk modulus, plateau stress, or maximal strain were confronted to Gibson and Ashby models. Friability was also evaluated via classical drum tests since they present a major drawback for the phenolic foam.

\section{Materials and Methods}

\subsection{Preparation of $P F$ samples}

The PFs were prepared from a resol-type phenolic resin with an acid catalyst as a curing agent and $n$-pentane as the blowing agent. The resin and surfactant were stirred for several minutes by using a high-speed mechanical mixer at room temperature until a homogeneous mixture was obtained. The blowing and the curing agents were added to the mixture under high mechanical stirring. The obtained viscous mixture was rapidly poured into a closed foaming mould and cured at $60^{\circ} \mathrm{C}$ for several hours and then post-cured at $80^{\circ} \mathrm{C}$ for several days. After post-curing, foam blocks with a dimension of $(120 \times 120 \times 60) \mathrm{mm}^{3}$ were obtained. Specific sampling preparation was required for each analysis, i.e., microstructural observation and mechanical testing. The effect of the density was studied on samples that were withdrawn from the same foam block.

Five PFs with poured density varying between $0.20 \mathrm{~g} . \mathrm{cm}^{-3}$ and $0.50 \mathrm{~g} . \mathrm{cm}^{-3}$ were prepared (Table 1 ). The poured density was fixed by dividing the mass of the reactional mixture introduced in the mould by the volume of the mould. After curing and post-curing, the density was calculated according to the mass and the volume of the resulting foam block. Whereas no change of the density value was noticed after the curing step, the removal of water occurring during the post-curing step induced a decrease of the foam density for all samples. Finally, to provide a mass evaluation independent from the adsorbed water, the foam samples were systematically dried at $70^{\circ} \mathrm{C}$ prior to any analysis. The density values discussed below correspond to the relative density $\left(d_{r}\right)$ 
based on the foam density after this drying step. The relative density corresponds to the ratio of the dry foam density $(d)$ by the density of the unfoamed solid $\left(d_{s}=1.20 \mathrm{~g} \cdot \mathrm{cm}^{-3}\right)$.

$$
d_{r}=\frac{d}{d_{s}}
$$

Table 1. Density (g.cm ${ }^{-3}$ ) values of five PF samples according to the manufacturing process steps. Values are given with a tolerance of 0.01

\begin{tabular}{l|ccccc}
\hline Sample & PF1 & PF2 & PF3 & PF4 & PF5 \\
\hline Poured density & 0.20 & 0.30 & 0.35 & 0.40 & 0.50 \\
\hline Density after curing & 0.20 & 0.30 & 0.35 & 0.40 & 0.49 \\
Density after post curing & 0.14 & 0.22 & 0.26 & 0.31 & 0.42 \\
Density after drying & 0.14 & 0.21 & 0.25 & 0.29 & 0.36 \\
\hline Relative density $\left(\boldsymbol{d}_{\boldsymbol{r}}\right)$ & 0.12 & 0.18 & 0.21 & 0.24 & 0.30 \\
\hline
\end{tabular}

\subsection{Measurements and characterization}

The morphological study of phenolic foams was performed by using a scanning electron microscope (SEM) FEI Quanta FEG 250, under high vacuum $\left(\approx 10^{-5}\right.$ Torr $)$, at a voltage of $10 \mathrm{kV}$. The samples were coated with a thin layer of palladium prior to the analysis. The samples were extracted from the central zone of each foam block and the observations were realized along the foaming direction. Image $\mathrm{J}$ software was used to complete the structural analysis. The analysis was performed on SEM images with a magnification of 40 , thus the surface analyzed was of $0.1283 \mathrm{~cm}^{2}$ and contained between 800 and 1000 cells depending on the sample. This number of cells is statistically satisfactory; hence for each sample only one representative image was studied.

The cells density of the foam $\left(N_{f}\right)$ corresponds to the ratio of the number of cells $(N)$ per unit of volume by the foamed polymer volume $\left(V_{f}\right)$ [22]:

$$
N_{f}=\frac{N}{V_{f}} .
$$


Batch process usually leads to the formation of nearly spherical cells [22]; hence, it is possible to assume an isotropic distribution of spherical cells. Under these conditions, the square root of the area density is cubed to estimate the number of cells per cubic centimeter of foam as described in Equation (3) [22]:

$$
N_{f}=\left(\frac{n}{A}\right)^{3 / 2}
$$

where $n$ is the number of cells in the micrograph of area $A$ in $\mathrm{cm}^{2}$.

Simple compression tests were performed by using an AGSX300 universal machine from Shimadzu Instruments. Tests were performed on cylindrical specimens with a diameter of $40 \mathrm{~mm}$ and a height of $40 \mathrm{~mm}$, at room temperature, with a speed of $1 \mathrm{~mm} . \mathrm{s}^{-1}$. Samples were placed between two compression plates to contain the sample during the test. To ensure significant and reproducible data, experiments were repeated at least twice.

The crushing tests were performed by using an AGSX300 universal machine from Shimadzu Instruments. Tests were performed on cylindrical specimens with a diameter of $40 \mathrm{~mm}$ and a height of $60 \mathrm{~mm}$, at room temperature, with a speed of $1 \mathrm{~mm} . \mathrm{s}^{-1}$. To ensure significant and reproducible data, experiments were repeated at least twice.

The 3-point bending tests were performed according to ASTM D790-03, on an AGSX300 universal machine from Shimadzu Instruments. The sample was supported by two cylinders with a radius of $5 \mathrm{~mm}$ and the force was applied by a cylindrical tip with a radius of $20 \mathrm{~mm}$. The distance between the supports was $80 \mathrm{~mm}$. The samples studied had the dimensions of $18 \times 18 \times 100 \mathrm{~mm}^{3}$. The tests were repeated at least twice to ensure reproducibility.

The bending stress $\left(\sigma_{f}\right)$ in the linear region is given by Equation (4):

$$
\sigma_{f}=\frac{3 F L}{2 b d^{2}}
$$


The deformation in flexion $\left(\epsilon_{f}\right)$ is given by Equation (5):

$$
{ }^{\epsilon} f=\frac{6 \Delta d}{L^{2}}
$$

The tangent modulus of elasticity $\left(E_{B}\right)$, is given by Equation (6):

$$
E_{B}=\frac{m L^{3}}{4 b d^{3}}
$$

where $L$ is the distance between supports in mm, $d$ is the thickness of the sample in $\mathrm{mm}, b$ is the width of the sample in $\mathrm{mm}, F$ is the force measured in $\mathrm{N}, \Delta$ is the deflection of the middle of the sample in $\mathrm{mm}$, and $m$ is the slope of the initial linear part of the force displacement curve.

Friability tests were performed according to the ASTM C421 standard, using a rotating drum, where 12 foam samples and 24 wood blocks with a dimension of $20 \mathrm{~mm}^{3}$ were introduced. Then, the drum was rotated at $60 \mathrm{rpm}$ for 10 minutes. The mass loss $\left(W_{l}\right)$ during the experiment or the pulverization ratio is determined thanks to Equation (7):

$$
W_{l}=\frac{W_{i}-W_{f}}{W_{i}}
$$

where $W_{i}$ and $W_{f}$ are the initial and the final masses of the foam samples, respectively.

\section{Results and Discussion}

\subsection{Morphological observations}

Morphological investigations were performed with the aim to determine the type and the characteristics of cells in the foams. Indeed, the average cell diameter, cells size distribution, or cell density might influence the mechanical properties although no clear explanations have been reported [12, 20]. 
DENSITY EFFECT ON MORPHOLOGICAL, MECHANICAL ... 51

Figure 1 displays SEM images of the five PF samples at two magnifications $(\times 40$ and $\times 300)$. All samples exhibit spherical-shaped cells with an opened-cell structure. Nevertheless, some holes are noticeable in the walls and their size decreases when the density increases. Hence, the higher the density, the less opened are the cells. Moreover, some small voids are present both on the cell walls and in the matrix. The presence of some holes in the phenolic foams may be explained by the presence of water in the phenolic foam formulation (generally 15-25\%wt.) as well as the water produced during the curing process [5].

In order to quantitatively study the morphology of the foam samples, the SEM images were analyzed by Image J. A cut off at $50 \mu \mathrm{m}$ was applied because too much noise was detected and the obtained results were then strongly influenced, thus the average cell size $\left\langle D_{\text {cell }}\right\rangle$ is overestimated. The cell size distribution and the average cell size of each foam sample are shown in Figure 2 and Table 2. The results confirm the previous observation of Figure 1; i.e., the average cell size decreases from $140 \mu \mathrm{m}$ to $100 \mu \mathrm{m}$ when increasing the relative foam density from 0.12 to 0.30, respectively (Table 2). With the same trend, the cell size distribution is narrower for the higher density with numerous small cells ( $\approx 100 \mu \mathrm{m}$, Figure 2 ). Cell density $\left(N_{f}\right)$ is kept at an almost constant value around $6.0 \pm 0.6 \times 10^{5}$ cells.cm ${ }^{-3}$ except for $d_{r}=0.12$ where $N_{f}$ is found equal to $4.2 \pm 0.4 \times 10^{5}$ cells.cm ${ }^{3}$.

Table 2. Average cells size, cell density and nucleation density obtained from image analysis as a function of the relative density. Values are given with a tolerance of $10 \%$

\begin{tabular}{l|ccccc}
\hline $\boldsymbol{d}_{\boldsymbol{r}}$ & $\mathbf{0 . 1 2}$ & $\mathbf{0 . 1 8}$ & $\mathbf{0 . 2 1}$ & $\mathbf{0 . 2 4}$ & $\mathbf{0 . 3}$ \\
\hline$<\boldsymbol{D}_{\text {cell }}>(\boldsymbol{\mu m})$ & 140 & 120 & 115 & 110 & 100 \\
$\boldsymbol{N}_{\boldsymbol{f}}\left(\times \mathbf{1 0}^{\mathbf{5}}\right.$ cells.cm \\
\hline
\end{tabular}


C. MOUGEL et al.

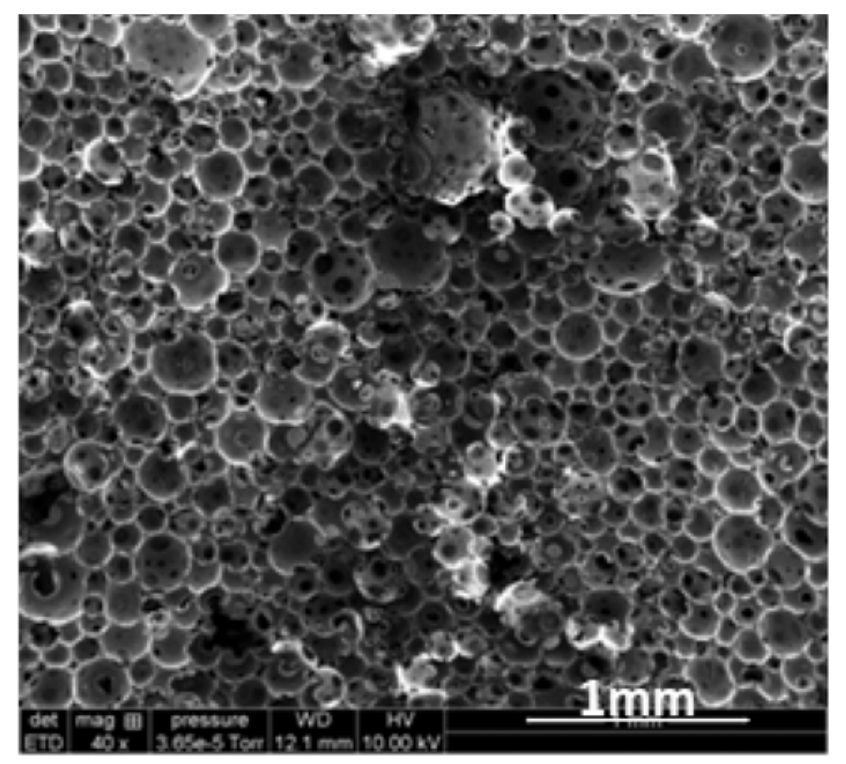

(a)

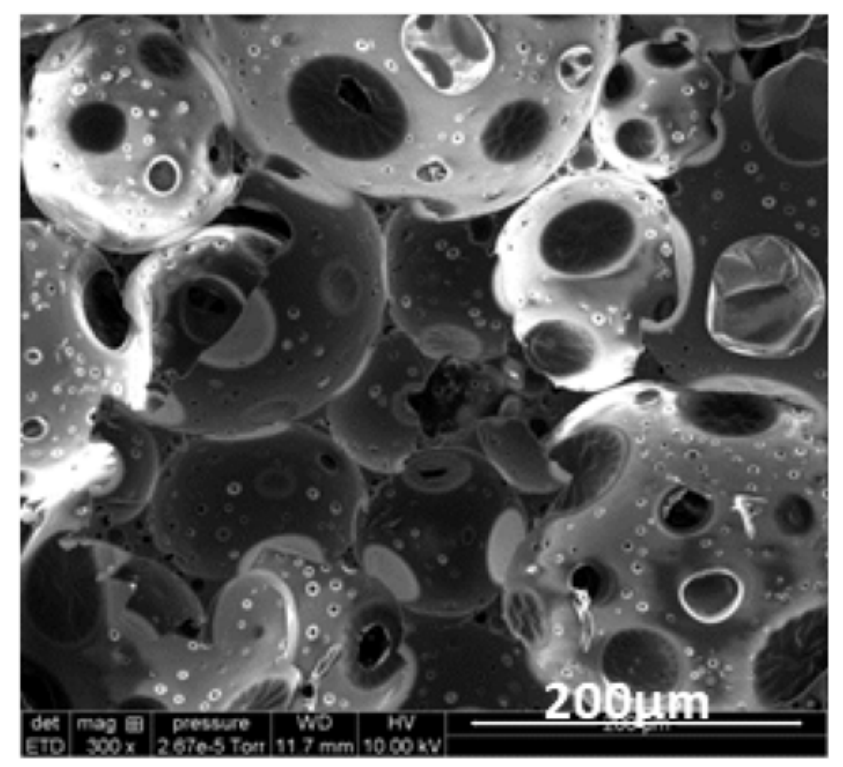

(b) 
DENSITY EFFECT ON MORPHOLOGICAL, MECHANICAL ... 53

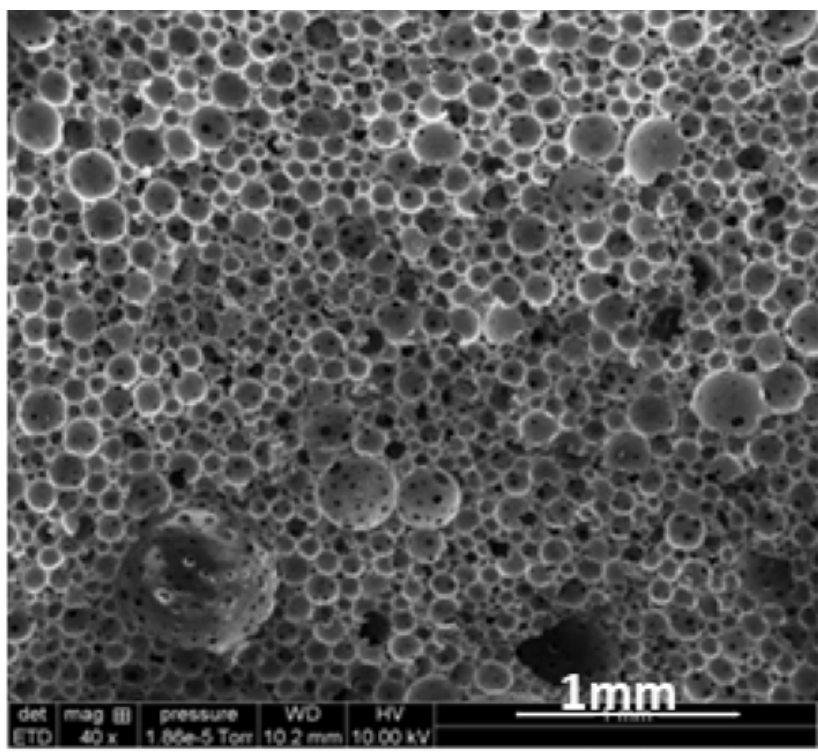

(c)

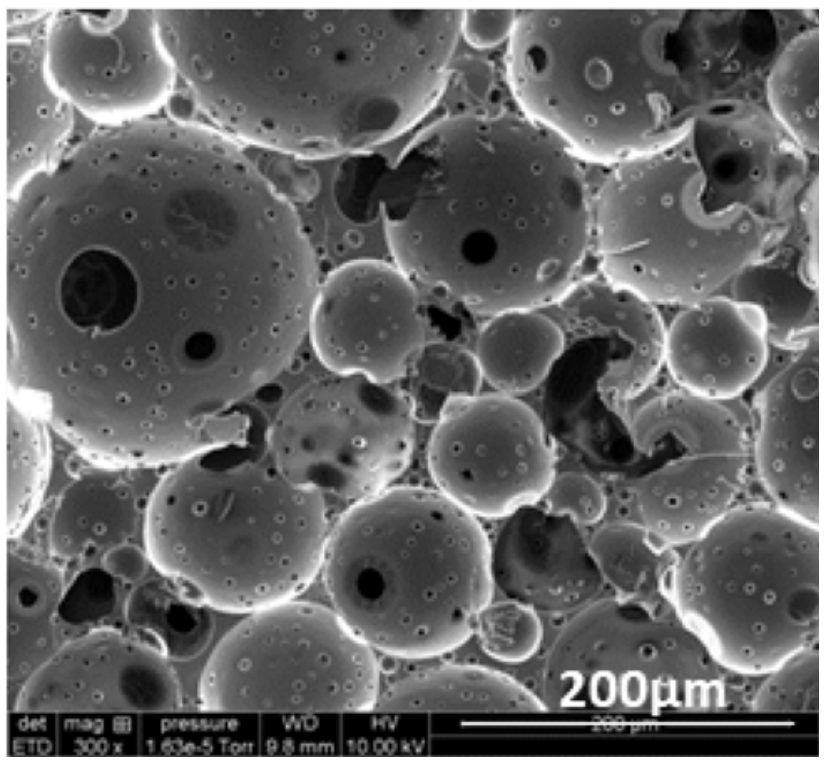

(d) 
C. MOUGEL et al.

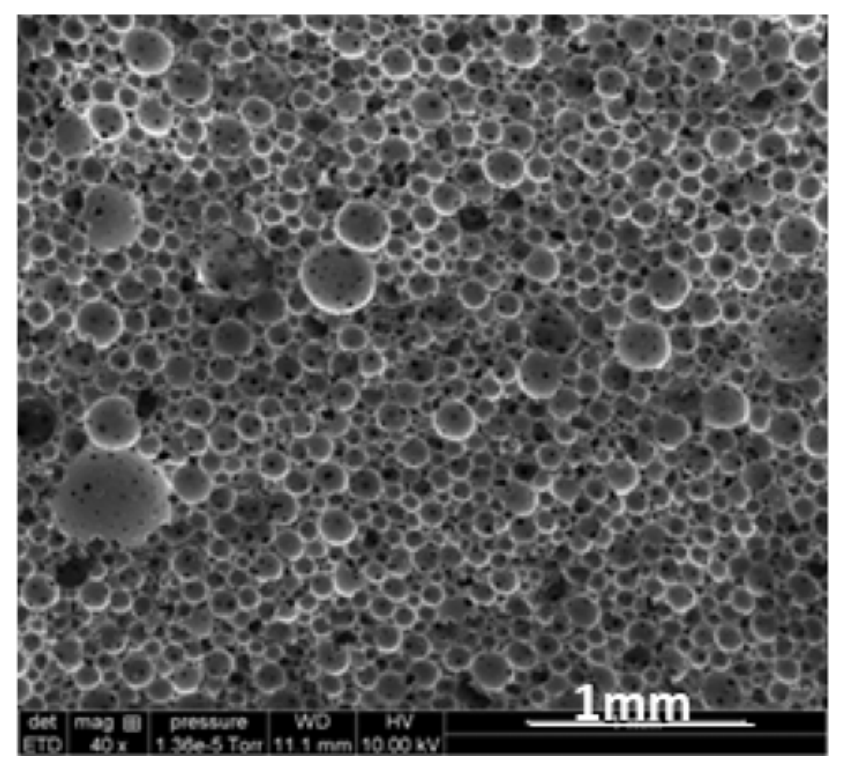

(e)

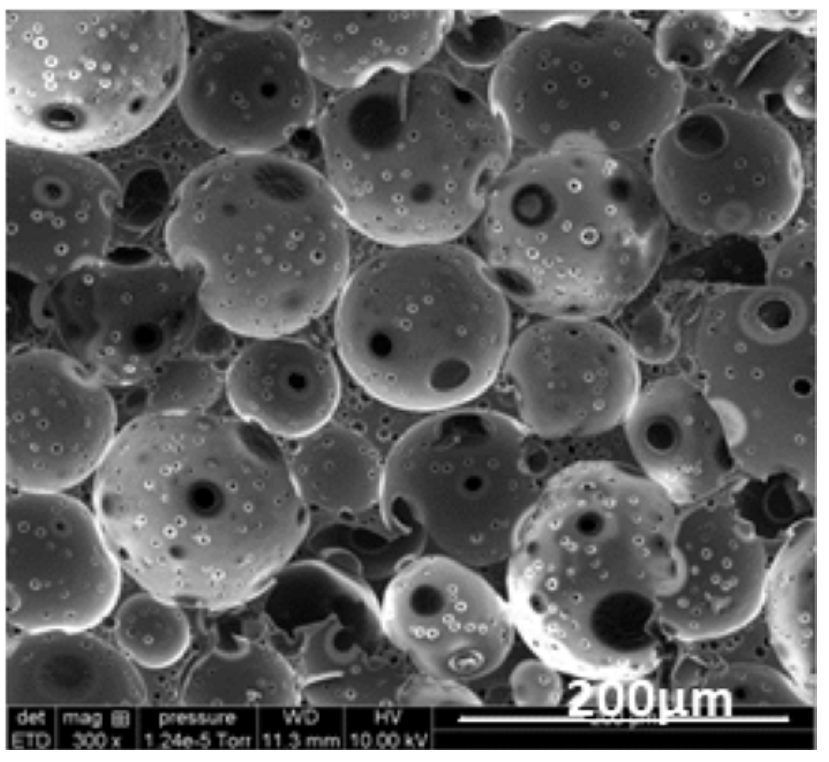

(f) 


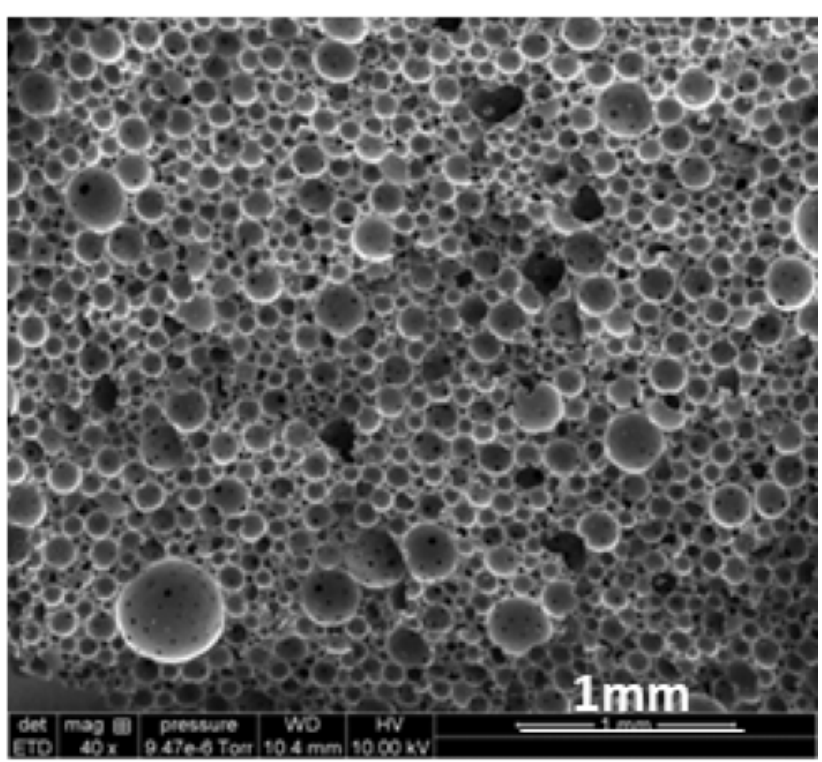

(g)

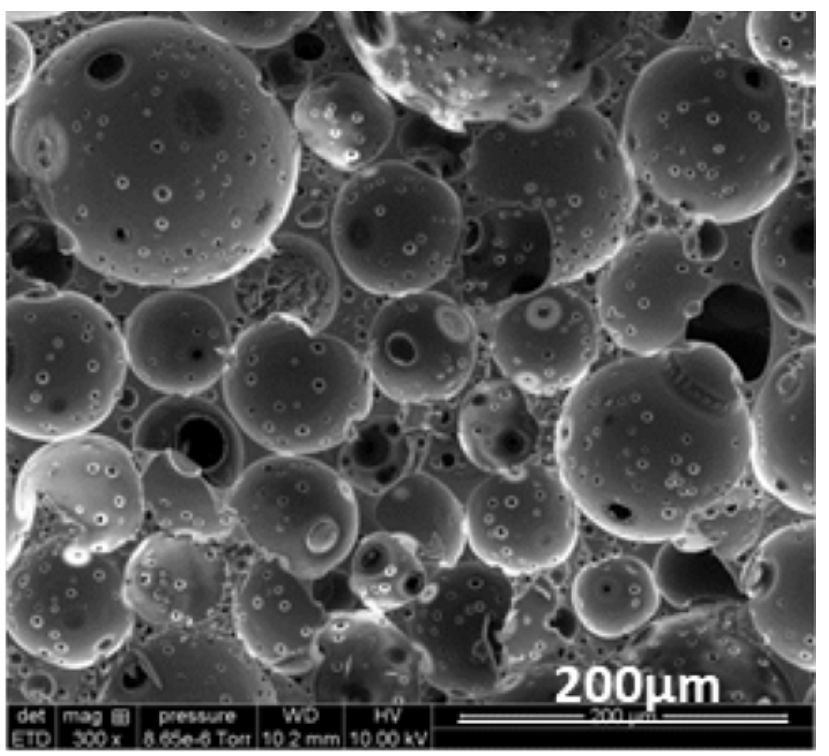

(h) 


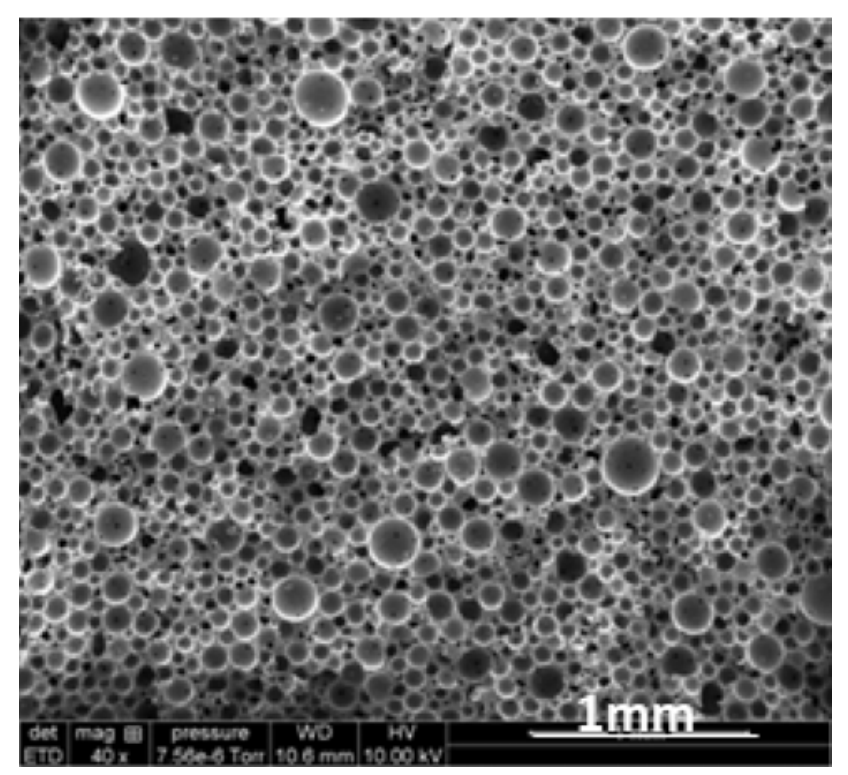

(i)

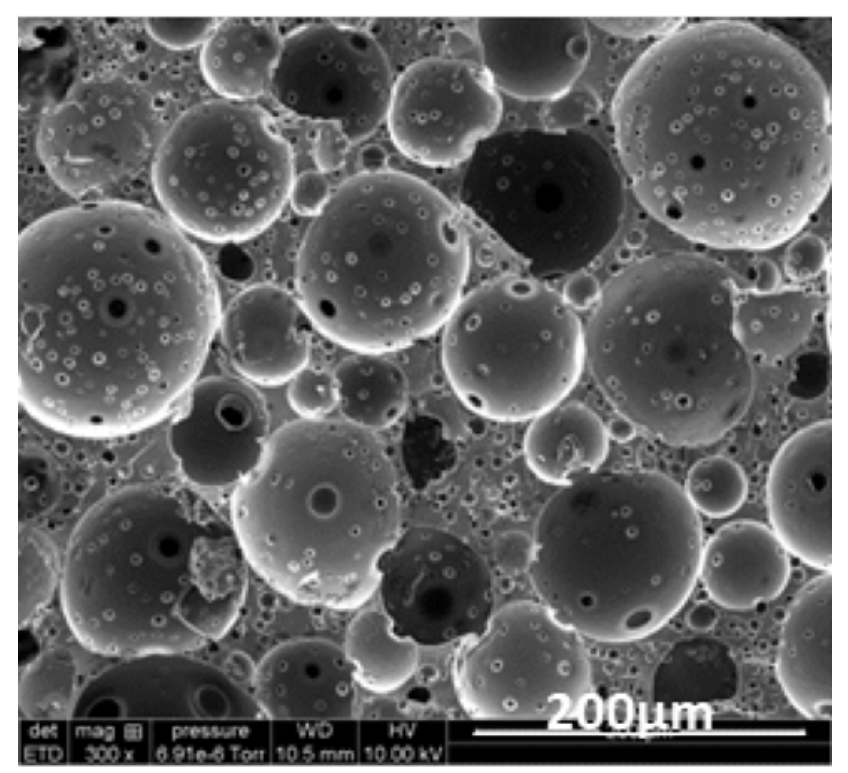

(j)

Figure 1. SEM images of PF with different relative densities 0.12 (a), (b); 0.18 (c), (d); 0.21 (e), (f); 0.24 (g), (h); and 0.30 (i), (j) with respect to magnification $(\times 40$ and $\times 300)$. 


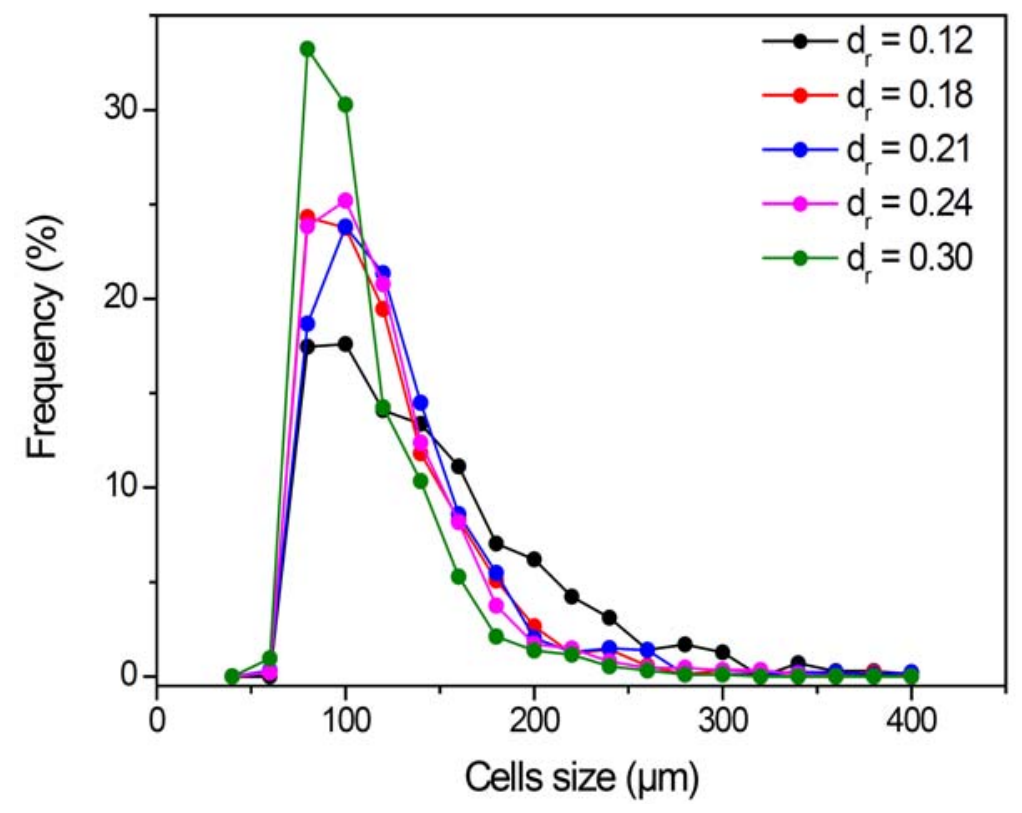

Figure 2. Size distribution as a function of the relative density of the foam.

\subsection{Mechanical properties}

\subsubsection{Physical and mechanical characteristics of the cured phenolic resin}

Here, the parameters of the un foamed dense state are determined, such as the density of the solid material, $d_{s}$, and the Young's modulus, $E_{s}$, as they are required to further apply the Gibson and Ashby model [3]. Regarding $d_{s}$, it is obtained for a cylinder $\varnothing=56 \mathrm{~mm}, h=33 \mathrm{~mm}$, and $m=88 \mathrm{~g}$ of the mixture formulation without blowing agent, cured at $70^{\circ} \mathrm{C}$ in a mould for $24 \mathrm{~h}$. A simple compression stress-strain curve reveals that $E_{s}=1 \mathrm{GPa}$ for this sample. However, three-point bending tests performed on two parallelepipedic samples provide a more accurate value of $E_{s}=1.8 \pm 0.2 \mathrm{GPa}$. Indeed, for compression test, the compression surface is much lower than the sample surface during the bending test, 
so the obtained value may be underestimated. Moreover, tensile tests have been also performed on flat specimens with rectangular crosssections; the obtained $E_{s}=1.0 \mathrm{GPa}$. In the following parts, the value of $E_{s}=1.8 \mathrm{GPa}$ is used for calculations.

\subsubsection{Crushing properties}

Figure 3 presents the compressive behaviour of the phenolic foam as a function of the relative density. All curves present the typical three stages of foam compression behaviour; at low strain, a linear region is observed corresponding to the foam linear elasticity. After that, a wide region where the stress is almost constant, called the plateau is observed. Finally, we can observe the densification region where the stress steeply increases.

Since the foam is confined in a metal casing when used as a shock absorber, the crushing test well represents the foam behaviour when applied in a shock absorber. Crushing properties are of great interest for energy absorption applications as the amount of energy that may be absorbed by the foam corresponds to the area under the curve in the elastic and plateau region but also depends on the acceleration during impact. Hence, the bulk modulus and plateau stress values are critical.

As expected [3], a strong effect of the density on the stress-strain curves is observed (Figure 3); increasing the relative density of the foams leads to an increase in the bulk modulus and the plateau stress but the densification will start at lower strain. 


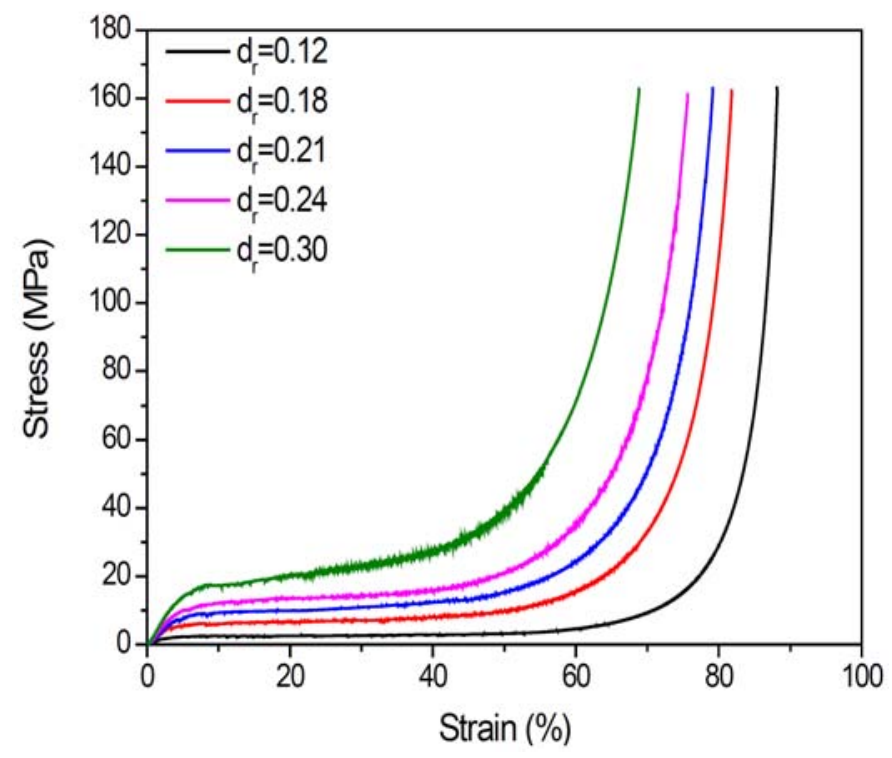

(a)

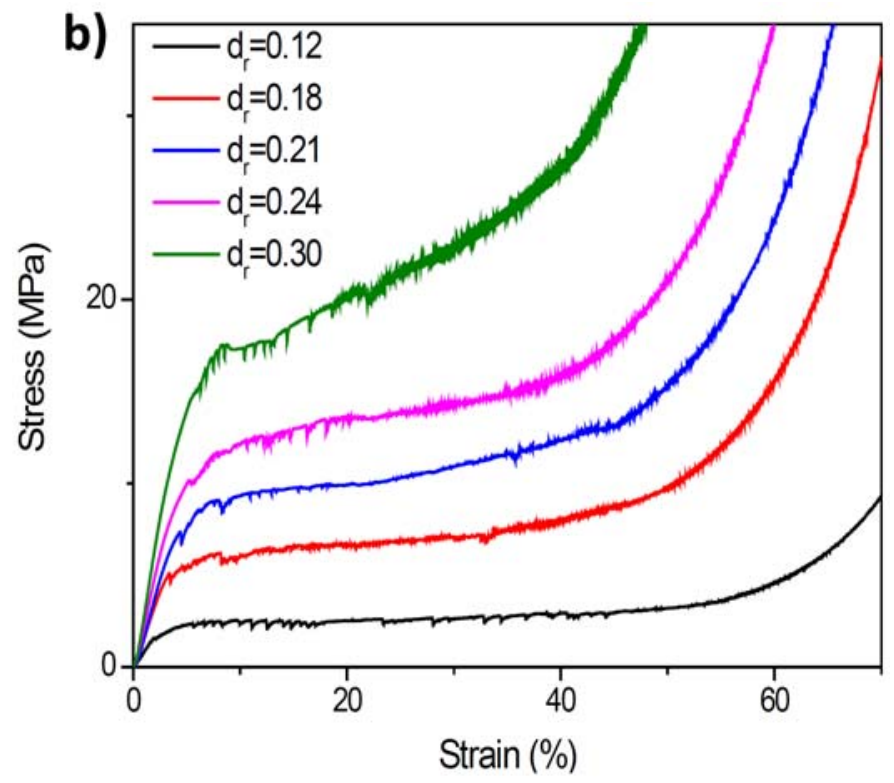

(b)

Figure 3. Compressive stress-strain as a function of the relative density of the foam (complete curve (a) and zoom (b)). 
Each region mentioned above is governed by a specific deformation mechanism. The linear elasticity is controlled by the cell walls bending in the case of opened cells and also by the stretching of the cell walls for closed cells [3]. At small deformations, the response of the foam is linear and elastic. Hence, it is possible to define the stress equal to the bulk modulus times the strain $(\sigma=K . \varepsilon)$. The plateau, in compression, is associated with the collapse of the cells by using different mechanisms according to the foam type. It has been identified that the plateau is determined by elastic buckling in the case of elastomeric foams, by the formation of plastic hinges for elasto-plastic foams, and by brittle crushing of the cells for brittle foams [3]. Finally, at large compressive strains, the opposing cell walls are in contact with each other, in which the cells are almost completely collapsed [3]. Additional strain compresses the solid itself, giving the final region, the densification, of rapidly increasing stress [3]. From Figure 3(b), compression curves exhibit the typical shape of brittle foams [3].

The characteristic parameters of the foam, in term of compression as well as their evolution as a function of the relative density, is determined by the following method (Table 3). First, the collapse plateau stress is $\left(\sigma_{p}\right)$ calculated for average stress values between 10 and $40 \%$ of strain and the maximal strain $\left(\varepsilon_{\max }\right)$ at $16 \mathrm{MPa}$ when the foam is completely compacted. This parameter and the bulk modulus $(K)$ are then compared to the Gibson and Ashby model. Linear elastic coefficients are related by the equation:

$$
K=\frac{E}{3(1-2 \nu)}
$$

As Poisson's coefficient is close to 0.33 (as will be demonstrated a posteriori), the bulk modulus is equivalent to Young's modulus $(K=E)$. Other experimental parameters are also characterized but cannot be predicted, i.e., the plateau modulus $\left(\gamma_{p}\right)$ defined as the slope of the 
plateau and the stress $\left(\sigma_{h}\right)$ recorded at the intersection between the plateau tangent and $y$-axis (Figure 4). The densification strain $\left(\varepsilon_{d}\right)$, where the foam is almost densified, is defined as the intersection between the tangent of the plateau and the tangent at maximal strain (Figure 4). Finally, the energy absorbed by the material is defined as the area below the stress-strain curve between $0 \%$ of strain and $\varepsilon_{d}$. The values of these experimental parameters (denoted exp) as a function of the density have been listed in Table 3. The data are determined from resultant curves of the crushing tests according to the density (Figure 3 and Figure 4). In this table, we also provide the values (denoted adj) adjusted from the different models (Equations (9)-(13)).

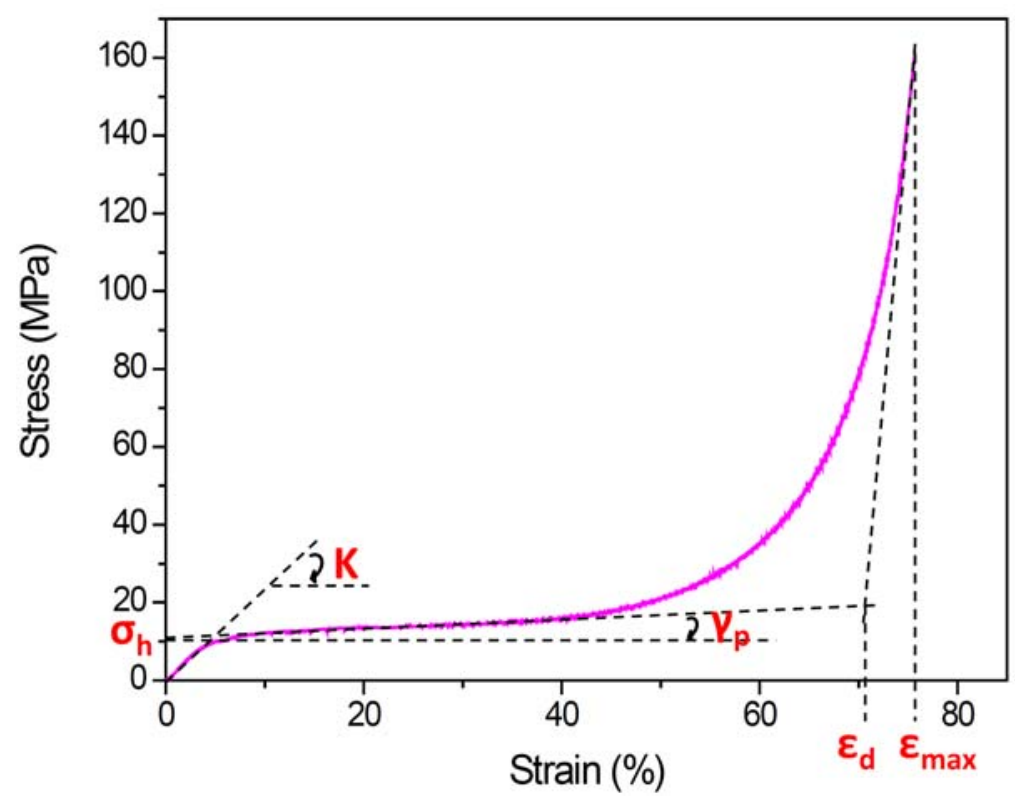

Figure 4. Determination of parameters from the crushing test curve. 
Table 3. Characteristic parameters obtained from compression tests according to the foam relative density. Values are given with a tolerance of $10 \%$

\begin{tabular}{|c|c|c|c|c|c|c|}
\hline & $d_{r}$ & 0.12 & 0.18 & 0.21 & 0.24 & 0.30 \\
\hline \multirow{2}{*}{ Linear elastic region } & $K_{\exp }(\mathrm{MPa})$ & 83 & 180 & 220 & 280 & 370 \\
\hline & $K_{\mathbf{a d j}}(\mathbf{M P a})$ & 68 & 150 & 220 & 290 & 450 \\
\hline \multirow{4}{*}{ Plateau region } & $\sigma_{h \exp }(\mathrm{MPa})$ & 2 & 5 & 8 & 11 & 14 \\
\hline & $\sigma_{p \exp }(\mathbf{M P a})$ & 3.0 & 7 & 11 & 14 & 22 \\
\hline & $\sigma_{p \mathbf{a d j}}(\mathbf{M P a})$ & 3 & 7 & 10 & 14 & 22 \\
\hline & $\gamma_{p \exp }(\mathrm{MPa})$ & 1 & 7 & 10 & 12 & 30 \\
\hline \multirow{5}{*}{ Densification region } & $\varepsilon_{d \exp }(\%)$ & 84 & 76 & 72 & 68 & 60 \\
\hline & $\varepsilon_{d \mathbf{a d j}}(\%)$ & 84 & 75 & 71 & 66 & 58 \\
\hline & $\varepsilon_{\max \exp }(\%)$ & 88 & 82 & 79 & 76 & 69 \\
\hline & $\varepsilon_{\max } \operatorname{adj}(\%)$ & 88 & 82 & 79 & 76 & 70 \\
\hline & $\begin{array}{l}\text { Energy absorbed } \\
\left(\text { MJ.m }^{-3}\right)\end{array}$ & 6 & 10 & 12 & 14 & 16 \\
\hline
\end{tabular}

The bulk modulus is determined in the linear elastic region between 1 and $2 \%$ of strain (Table 3 ). Indeed, the typical initial behaviour is not exactly linear because of geometrical irregularities and inhomogeneities on the sample surface. Moreover, Gibson and Ashby [3] note that this method often underestimates the bulk modulus. Instead, they encourage using the slope during release after starting the plateau regime. While such a method eliminates the problem of sample adjustment to the shaper, and can thus provide a higher value of the slope, it is unclear that it will provide the actual bulk modulus and not a bulk modulus of a partially restructured material. As a consequence, only the initial slope has been considered in the present study, despite the shortcoming of this method. 
Figure 5(a) shows Young's modulus (equal to the bulk modulus) calculated from the experimental data as a function of the relative density against the Gibson and Ashby model. Literature values are also reported in Figure 5. The Young's modulus is described by a quadratic function of the relative density in accordance with the model described in Equation (9). Indeed, a correlation coefficient of 0.97 was obtained although only five points were used. The best parameter obtained for the adjusted model is a constant value of $C_{1} \cdot E_{s}$ equal to $5.0 \mathrm{GPa}$. Hence, considering $E_{s}=1.8 \mathrm{GPa}$, the model is consistent with a coefficient $C_{1} \approx 2.8$ instead of 1 as observed by Gibson and Ashby [3]. Gibson and Ashby noticed that the presence of porosity in the struts in ceramic materials could lead to a modified $C_{1}$ value, as Young's modulus for dense materials (without porosity) was used [3]. From SEM observations, we also observe a second scale of porosity in the wall as well as in the struts, which can explain this difference. Moreover, the strut shape [23], as well as the structural heterogeneity inside the strut [20], can also influence the coefficient of proportionality.

$$
\frac{E}{E_{s}}=C_{1} d_{r}^{2}, \quad \text { where } C_{1} \text { is a constant } C_{1} \approx 1
$$

Figure 5(b) shows the bi-logarithm of Young's modulus versus the relative density for experimental and literature values and their respective quadratic adjustment. Literature values are more scattered but still consistent with a quadratic adjustment with $C_{1} \cdot E_{s}$ equal to $3500 \mathrm{MPa}$. Such scattering is expected because each value comes from different studies. Nevertheless, all values are consistent and the Young's modulus is described by a quadratic power law of the relative density (Equation (9)). 


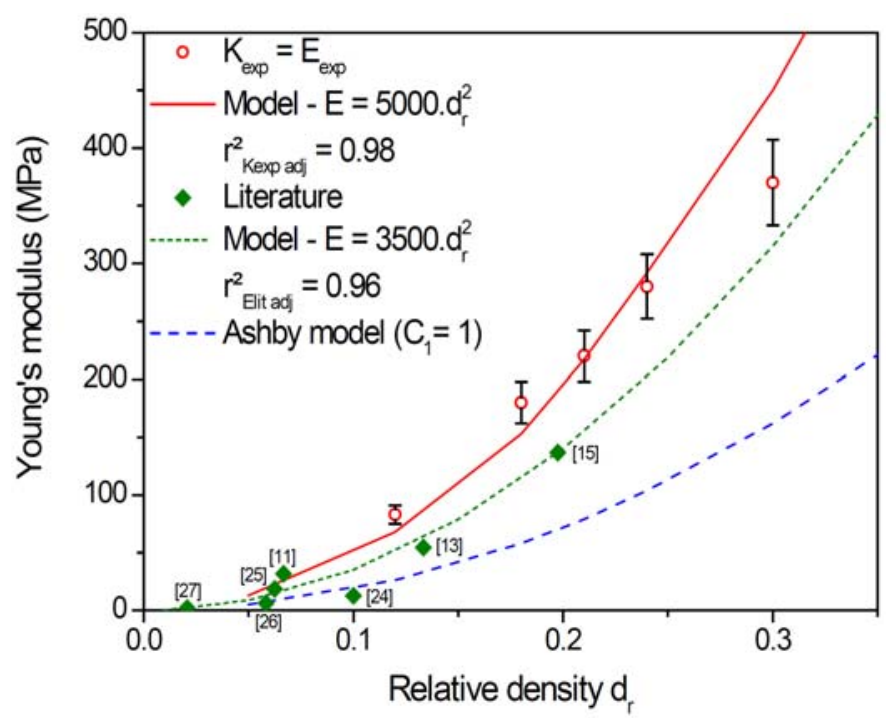

(a)

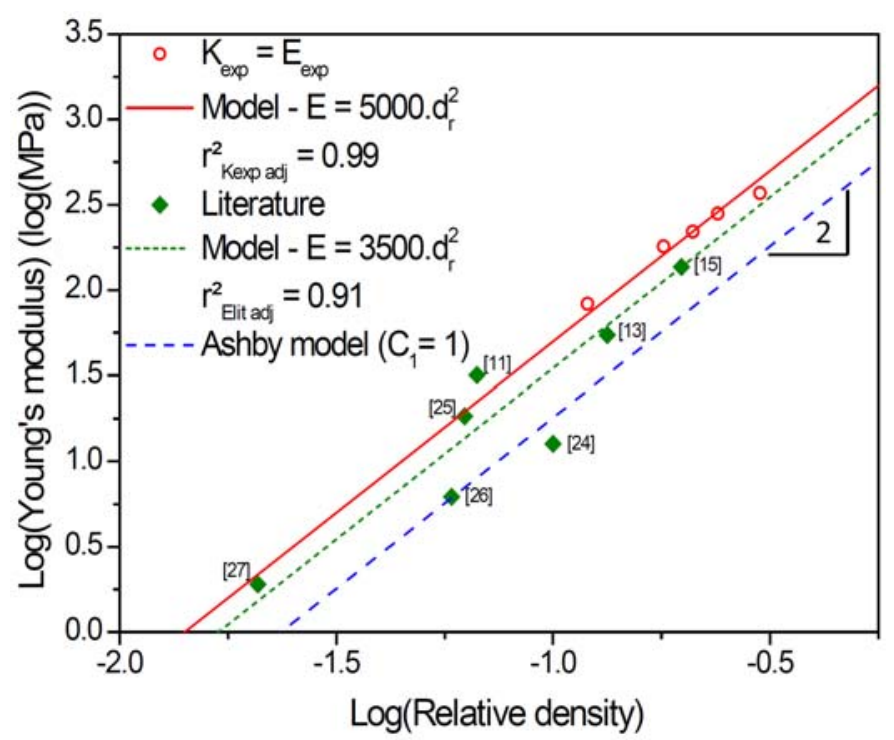

(b)

Figure 5. Evolution of Young's modulus as a function of the relative density (a) and representation in logarithm scale (b). Symbols are values from crushing tests (red empty circle) and from literature (green rhombus) and the line, the associated adjusted model: crushing tests (red line) and from literature (green dot line) [11, 13, 14, 15, 24, 25, 26]. Blue dash line represents the Gibson and Ashby prediction [3]. 
The density also significantly influences the plateau parameters; the collapse stress, the length of the plateau and the plateau modulus vary from 3.3 to $21.6 \mathrm{MPa}$, from 57 to $33 \%$ of strain and from 1.1 to $30 \mathrm{MPa}$ for $d_{r}=0.12$ and $d_{r}=0.30$, respectively.

Moreover, we observe that increasing the density leads to the emergence of a slope in the plateau region. This could be due to the thickness variation of the cell struts, which increases with the density. Indeed, according to their thicknesses, they will break under different stresses while struts with identical thicknesses will break at the same stress leading to a long and flat plateau [19]. Another reason for the plateau rising with strain is that the number of closed cells in the foam increased with the density. Gibson and Ashby have observed that for totally opened-cell polyethylene foams, the cells collapse at almost constant load. For closed-cell polyethylene foams, the compression of the gas within the cells, in addition to the membrane stresses in the cell faces, provides a stress-strain curve rising with the strain [3]. At relatively low densities, the $\mathrm{PF}$ is a fully open-cell type, while the increase of the density induces the formation of closed cells. This is in accordance with SEM observation in Figure 1.

Figure 6 shows the variation of the collapse plateau stress versus the relative density. The Gibson and Ashby model for open-cell brittle foam (Equation (10)) with a power law $d_{r}^{3 / 2}$ does not match the experimental data of the collapse plateau stress. This result points out that this model is not relevant to the present data. On the contrary, the Gibson and Ashby model of open-cell elastomeric foam (Equation (11)) matches quite well the experimental data with a correlation coefficient of 0.99 ; a constant value of $240 \mathrm{MPa}$ for $C_{3} . E_{s}$ was obtained from the adjusted curve, leading to a coefficient $C_{3}$ around 0.13 (considering $E_{s}=1.8 \mathrm{GPa}$ ) instead of 0.05 as determined by Gibson and Ashby [3]. 
Conversely, when considering $C_{1}$ and $C_{3}$ equal to 1 and 0.05, respectively, as defined by Gibson and Ashby, we obtain values of 5.0GPa and $4.8 \mathrm{GPa}$, respectively, for Young's modulus of the solid. These two values are thus in agreement and $E_{s}=1.8 \mathrm{GPa}$ might be an underestimate.

Finally, the Gibson and Ashby model for elastomeric foams appears to be quite surprisingly adapted to describe the PF behaviour instead of the one for opened-cell brittle foam. It is not possible to explain this nontypical behaviour

$$
\begin{aligned}
& \frac{\sigma_{c r}}{\sigma_{f s}}=C_{2} d_{r}^{3 / 2}, \quad \text { where } C_{2} \text { is a constant } C_{2} \approx 0.2, \\
& \frac{\sigma_{e l}}{E_{s}}=C_{3} d_{r}{ }^{2}, \quad \text { where } C_{3} \text { is a constant } C_{3} \approx 0.05
\end{aligned}
$$

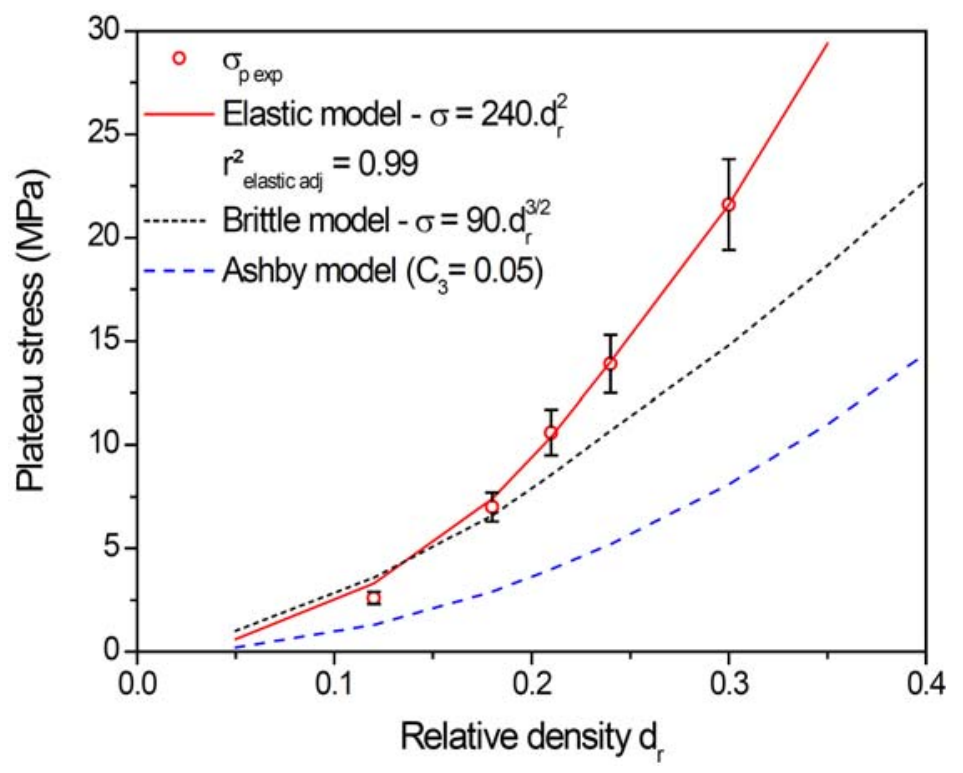

Figure 6. Evolution of the plateau stress as a function of the relative density: red symbols are values from crushing tests and the lines the adjusted models; red elastic model and black dot brittle model. Blue dash line represents the Gibson and Ashby prediction [3]. 
In the last part of the stress-strain response (Figure 3), the stress rapidly increases likely because the strain transforms the foam sample to a quasi-dense material. The densification region can be evaluated due to two parameters: the densification strain $\left(\varepsilon_{d}\right)$ and the maximal strain $\left(\varepsilon_{\max }\right)$. The relation found for $\varepsilon_{d}$, where the densification of the material begins, is given in Equation (12). Surprisingly, this relation in Gibson and Ashby theory corresponds to the relation for maximal strain. In our case, $\varepsilon_{\max }$ is represented by a more physically satisfactory relation defined in Equation (13), as this one means that the densified foam has almost the same density as the dense state. Hence, it is possible to consider that the load applied to compress the foam was sufficiently high. Moreover, $\varepsilon_{d}$ and $\varepsilon_{\max }$ decrease when the density increases.

The absorbed energy by the material is defined as the area below the stress-strain curve between $0 \%$ of strain and $\varepsilon_{d}$. Values are reported in Table 3. As expected, the amount of energy absorbed increases with the density.

$$
\begin{gathered}
\varepsilon_{d}=1-1.4 d_{r}, \\
\varepsilon_{\max }=1-d_{r} .
\end{gathered}
$$




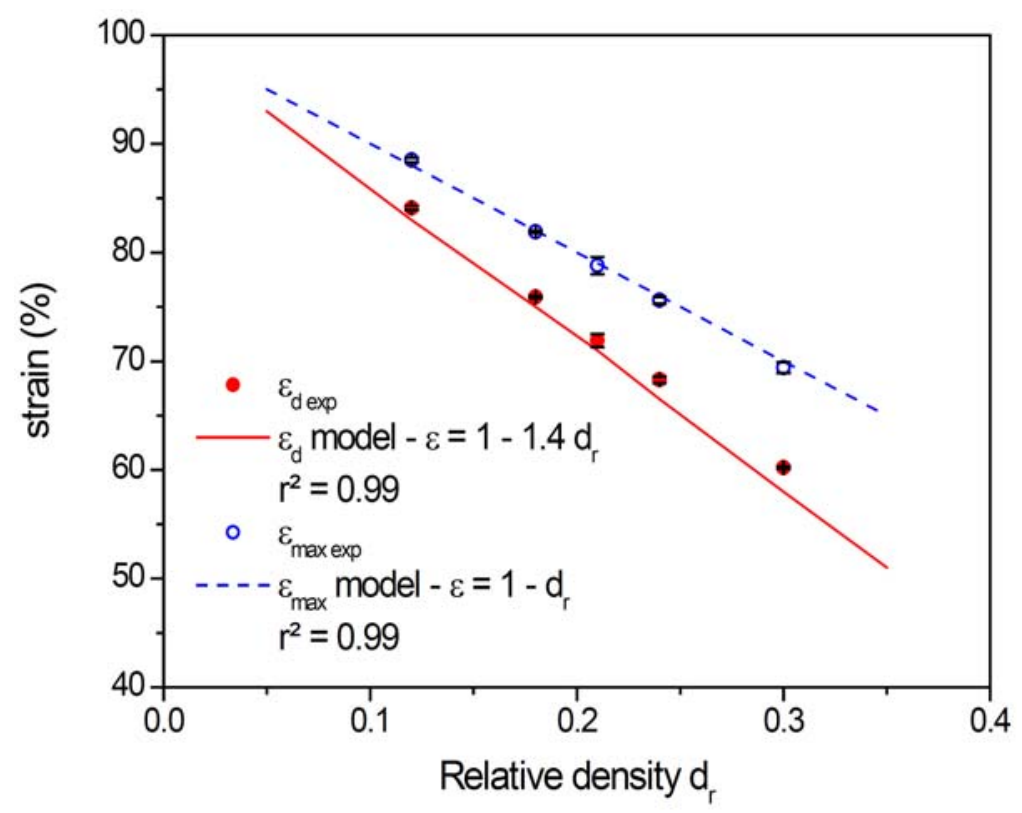

Figure 7. Evolution of densification strain (red) and maximal strain (blue) as a function of the relative density: symbols are values from crushing tests and the lines correspond to the adjusted model.

\subsubsection{Compressive strength}

In the literature, the authors principally evaluate the compressive strength and do not perform crushing tests. Hence, to compare the compressive strength $\left(\sigma_{c}\right)$ of our PF to the literature, in addition to Young's modulus, some simple compression tests have been performed (Figure 8(a)). The experimental values are in agreement with the literature and even slightly higher. Moreover, the values from both sources are plotted in a bi-logarithm scale (Figure 8(b)) and follow a quadratic law as suggested by the results obtained for the plateau stress. As seen for Young's modulus, the literature values for compressive report more disparities than the values obtained in this work and a lower proportionality coefficient. 


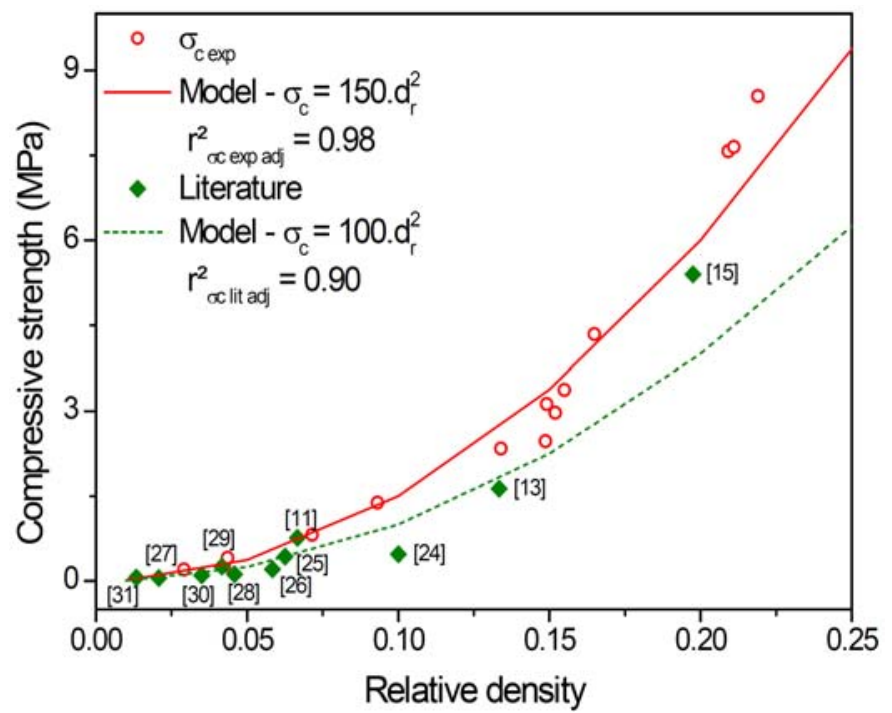

(a)

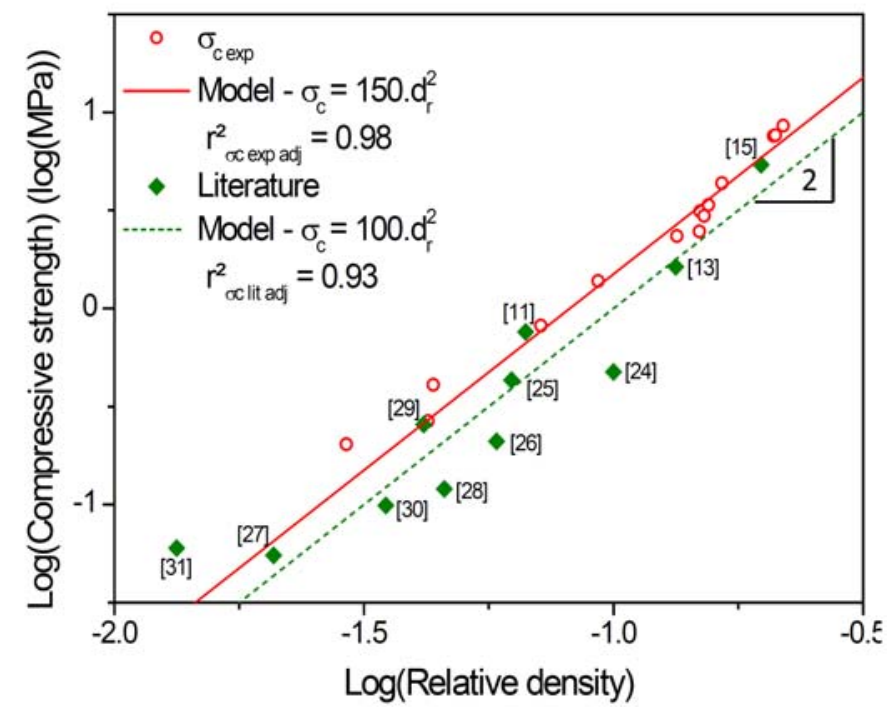

(b)

Figure 8. Evolution of the compressive strength as a function of the relative density (a) and representation in bi-logarithm scale (b). Symbols are values from simple compression tests (red empty circle) and from literature (green rhombus) and the line, the associated adjusted model: simple compression tests (red line) and from literature (green dot line) [11, 13, 14, 15, 24, 25, 26, 27, 28, 29, 30]. 


\subsubsection{Bending properties}

The 3-point bending test was performed in order to determine the Young's moduli according to the relative densities and to compare them with the ones deduced from bulk modulus. In such experiment, the flexural strain can be related to the deflection and the flexural stress to the load. In the case of phenolic foam, the curve does not show any significant softening before breaking since phenolic foam is brittle. Flexural strength and flexural stress at break are thus identical. The

stress at break $\left(\sigma_{\text {break }}\right)$, strain at break $\left(\varepsilon_{\text {break }}\right)$, and Young's modulus ( $E_{B}$ defined as the slope between 0.2 and 0.5 of strain) for each relative density are reported in Table 4.

As expected, the stress at break increases with the density from $1.9 \mathrm{MPa}$ at $d_{r}=0.12$ up to $8.0 \mathrm{MPa}$ at $d_{r}=0.30$ to the opposite, the strain at break stays at an almost constant value equal to $2.3 \pm 0.2$, independent of the relative density. The Young's modulus is observed to increase when the relative density increases and the obtained values are comparable to those found by compressive stress, except for the highest density studied. Experimental values are adjusted using the Gibson and Ashby model according to Equation (9). Figure 9 presents the experimental results, the resultant adjusted model, and the results obtained from the compressive tests. The Young's modulus is always correctly described by a quadratic function of the relative density, but the constant value $\left(C_{1} \cdot E_{s}\right)$ is found to be equal to $4 \mathrm{GPa}$. Hence, the model is consistent with a coefficient $C_{1} \approx 2.2$ instead of 1 . This deviation could be explained by the same reasons mentioned above for the bulk modulus. Nevertheless, all results tend toward an estimation of the dense-state Young's modulus to be greater than the one found from dense-state experiments. Hence, $E_{s}$ is probably underestimated. 
Table 4. Young's modulus, strain at break as well as stress at break obtained from of 3-points bending tests as a function of the relative density. Values are given with a tolerance of $10 \%$

\begin{tabular}{l|ccccc}
\hline $\boldsymbol{d}_{\boldsymbol{r}}$ & $\mathbf{0 . 1 2}$ & $\mathbf{0 . 1 8}$ & $\mathbf{0 . 2 1}$ & $\mathbf{0 . 2 4}$ & $\mathbf{0 . 3 0}$ \\
\hline $\boldsymbol{E}_{\boldsymbol{b} \text { exp }}(\mathbf{M P a})$ & 71 & 190 & 200 & 260 & 270 \\
$\boldsymbol{E}_{\boldsymbol{b} \text { th }}(\mathbf{M P a})$ & 54 & 123 & 174 & 234 & 360 \\
\hline$\sigma_{\text {break }}(\mathbf{M P a})$ & 1.9 & 4.5 & 4.9 & 6.4 & 8.0 \\
$\varepsilon_{\text {break }}(\%)$ & 2.4 & 2.5 & 2.2 & 2.4 & 2.4 \\
\hline
\end{tabular}

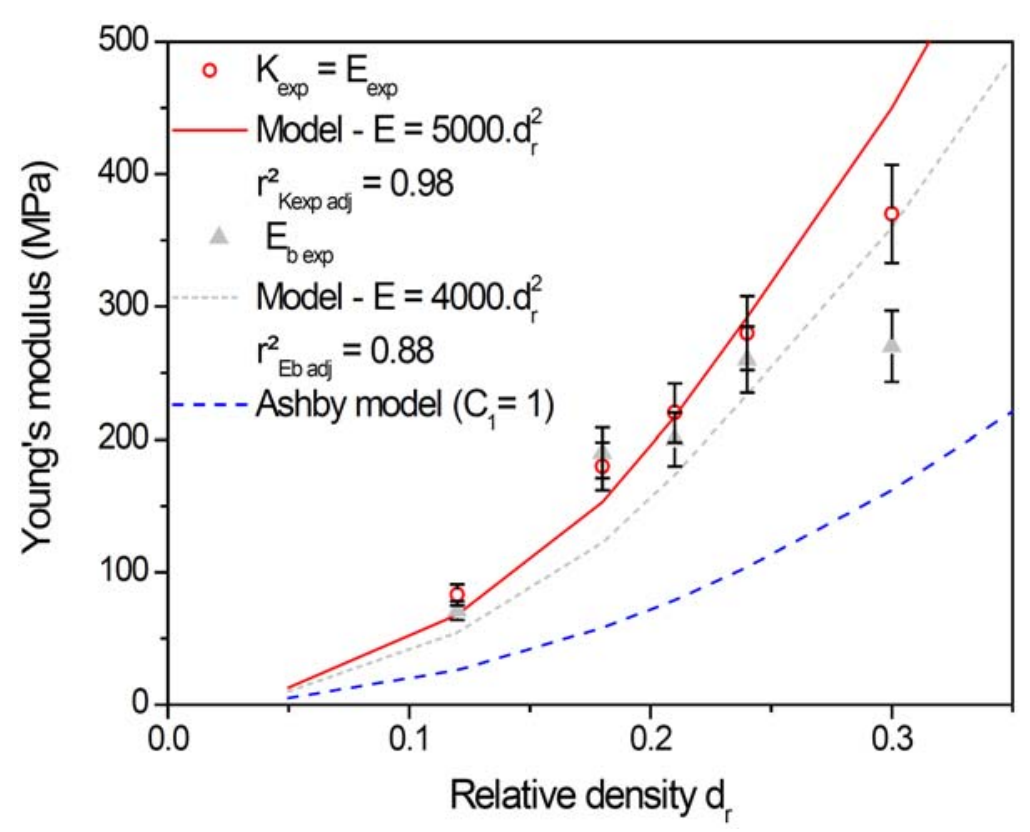

Figure 9. Evolution of Young's modulus from crushing tests (red) and from 3-point bending tests (grey) as a function of the relative density. Symbols are values from crushing tests (red empty circle) and from 3-point bending tests (grey triangle) and the line, the associated adjusted model: crushing tests (red line) and from 3-point bending tests (grey dot line). Blue dash line represents the Gibson and Ashby prediction [3]. 


\subsubsection{Computation of Poisson's coefficient on the basis of crushing tests and 3-point bending tests}

Another important parameter characterizing the foam is Poisson's coefficient because it allows characterizing the contraction of the material perpendicular to the direction of the applied load. It can be deduced from the bulk modulus $(K)$ and Young's modulus $(E)$ according to Equation (14).

$$
\nu=\frac{3 K-E}{6 K} .
$$

Based on the crushing and 3-point bending tests, all the results are in the vicinity of 0.33 , as expected by the Gibson and Ashby model as shown in Table 5. From the experimental values, all samples present a Poisson's coefficient of $0.35 \pm 0.03$. Hence, the bulk modulus can be considered equal to Young's modulus.

Table 5. Poisson's coefficients from crushing tests and 3 points bending tests. Values are given with a tolerance of $10 \%$

\begin{tabular}{l|ccccc}
\hline $\boldsymbol{d}_{\boldsymbol{r}}$ & $\mathbf{0 . 1 2}$ & $\mathbf{0 . 1 8}$ & $\mathbf{0 . 2 1}$ & $\mathbf{0 . 2 4}$ & $\mathbf{0 . 3 0}$ \\
\hline $\boldsymbol{K}(\mathbf{M P a})$ & 83 & 180 & 220 & 280 & 370 \\
$\left.\mathbf{5 0 0 0 . \boldsymbol { d } _ { \boldsymbol { r } }}{ }^{2} \mathbf{M P a}\right)$ & 68 & 153 & 217 & 292 & 450 \\
$\boldsymbol{E}_{\boldsymbol{b}}(\mathbf{M P a})$ & 71 & 190 & 200 & 260 & 270 \\
$\left.\mathbf{4 0 0 0 . \boldsymbol { d } _ { \boldsymbol { r } }}{ }^{\mathbf{2}} \mathbf{M P a}\right)$ & 54 & 123 & 174 & 234 & 360 \\
\hline $\boldsymbol{V}_{\text {exp }}$ & 0.36 & 0.32 & 0.35 & 0.35 & 0.37 \\
$\boldsymbol{V}_{\text {model }}$ & 0.37 & 0.37 & 0.37 & 0.37 & 0.37 \\
\hline
\end{tabular}

\subsubsection{Friability}

Friability remains the main drawback of rigid and brittle foams. This property is particularly crucial for phenolic foams as it can limit their applications [4]. Since the friability becomes more important for lowdensity foams, the literature essentially contains reported studies on 
phenolic foams with a density below 0.1 [12]. Nevertheless, it is difficult to compare the obtained results with the literature because on one hand different tests are used to evaluate the friability; e.g., the abrasion test against sandpaper [31,32] or the drum test [11,33]. On the other hand, the results from the drum test (chosen for this study) depend on the density of the wood cubes, their surface state, etc.; hence, the obtained values are relative.

The phenolic foam of various densities was submitted to the friability test. Results are shown in Figure 10. Although the mass loss was 9.3\%wt. for a relative density of 0.12 , this value significantly decreases to $1.0 \% \mathrm{wt}$. with the increase in the relative density up to 0.30 . As the resin content is higher for high-density foam, the cell walls are thicker and can sustain higher stresses before breaking. Moreover, the cell size is lower making the buckling phenomenon more difficult.

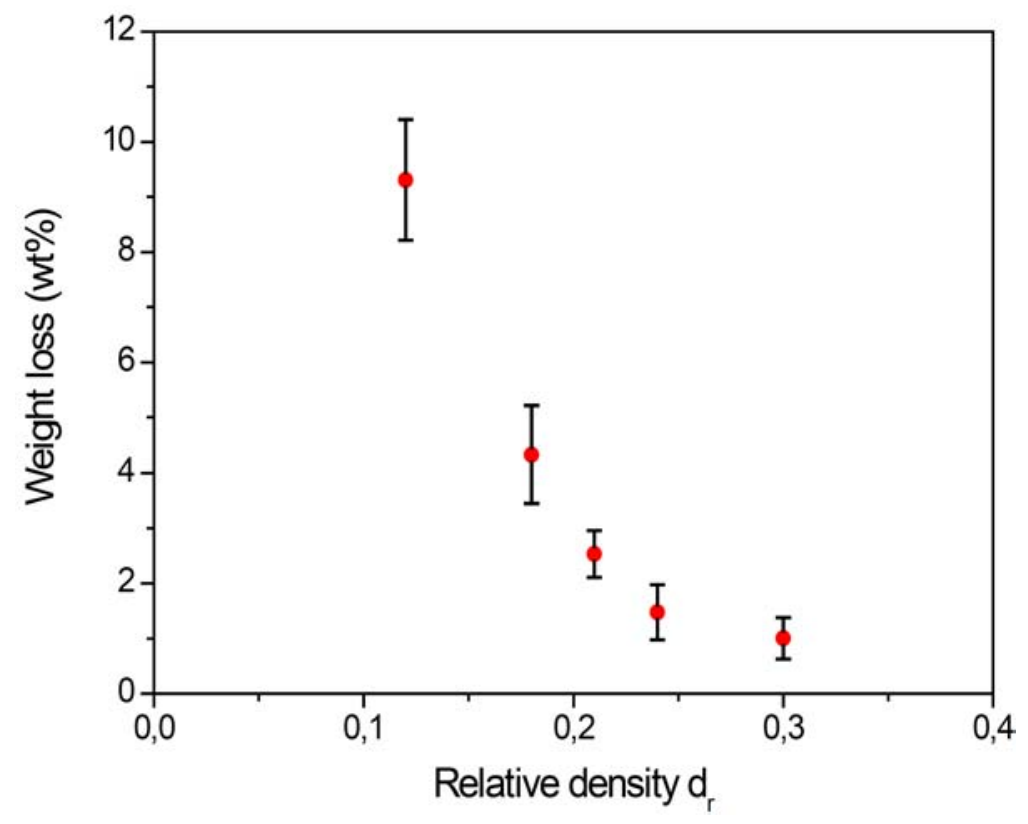

Figure 10. Mass loss during friability tests as a function of the relative density of the foam. 


\section{Conclusion}

The main objective of this work was to investigate the properties of phenolic foams (PFs) with relatively high densities $\left(d>0.1 \mathrm{~g} . \mathrm{cm}^{-3}\right)$. We investigated the effect of the density on the morphological, compressive, and friability properties of PFs in which the relative densities varied from 0.12 to 0.30 . The compressive properties were compared to the Gibson and Ashby models.

SEM results of PF revealed spherical-shape cells with an opened-cell type structure, which agrees with the literature. Image analysis provided quantitative values and revealed that as the relative density increased up to 0.30 , the mean cell size decreased from $140 \mu \mathrm{m}$ to $100 \mu \mathrm{m}$ with a narrower cell size distribution. Cell density remained constant with $6.0 \pm 0.3 \times 10^{5}$ cells.cm ${ }^{-3}$ except for the lowest density studied where it decreases to $4.2 \times 10^{5}$ cells.cm ${ }^{-3}$.

Regarding the mechanical properties, Young's modulus has been deduced from bulk modulus and determined by 3-point bending tests. The results are consistent with those found in the literature and qualitatively agree with Gibson and Ashby's model as Young's modulus obeys a quadratic law with respect to the relative density. It has been evaluated at $E=5000 .\left(d_{r}\right)^{2}$ and at $E=4000 .\left(d_{r}\right)^{2}$ for crushing and 3 -point bending tests, respectively. To quantitatively evaluate the model, Young's modulus of unformed cured materials is required and was found to be equal to $1.8 \pm 0.2 \mathrm{GPa}$. Hence, the model is in quantitative disagreement with the proportionality coefficient by a factor 2.8 and 2.2 in the case of compressive and 3-point bending tests, respectively.

Plateau stress has been also evaluated following Gibson and Ashby model. First, the case of brittle foam was studied and clearly appeared not adapted to our case of study. Then, the model for elastomeric foam was applied and our results are in good agreement with the proposed 
model. This time again, plateau stress is a quadratic function of the relative density. It has been evaluated around $\sigma_{e l}=240 . d_{r}{ }^{2}$. Hence, using the value of $E_{s}$ equal to $1.8 \mathrm{GPa}$, a divergence of factor 2.5 on the proportionality coefficient is found with the model.

The densification region has been also evaluated and according to the Ashby and Gibson model, the strain at maximal densification is $\varepsilon_{\max }=1-d_{r}$, with $a=1.4$. In our case, a value of 1 is found which is more physically satisfactory. Indeed, it means that the density of the compressed foam is equal to the dense material.

Finally, friability results showed a strong dependence on the density. Indeed, the mass loss for a relative density of $0.30(1.0 \% \mathrm{wt}$.) is almost ten times lower than that for $0.12(9.3 \%$ wt.) because the cell walls are thinner for low density and thus more fragile. For relatively high density, the friability becomes less problematic.

\section{Acknowledgements}

The authors gratefully acknowledge Robatel Industries and ANRT for providing the financial support for this work (CIFRE No 2014/0969).

\section{References}

[1] A. H. Landrock, Handbook of Plastic Foams: Types, Properties, Manufacture and Applications, Elsevier Science, New York, 1995.

[2] A. Gardziella, L. A. Pilato and A. Knop, Phenolic Resins: Chemistry, Applications, Standardization, Safety and Ecology, Springer, Berlin, 2000.

DOI: https://doi.org/10.1007/978-3-662-04101-7

[3] L. J. Gibson and M. F. Ashby, Cellular Solids: Structure and Properties, Cambridge University Press, New York, 1999.

DOI: https://doi.org/10.1017/CBO9781139878326

[4] L. Pilato, Phenolic Resins: A Century of Progress, Springer, Berlin, 2010.

DOI: https://doi.org/10.1007/978-3-642-04714-5

[5] J. D. Carlson, V. J. Wojtyna, E. W. Kifer and J. P. Colton, Phenolic Foam and Composition and Method for Preparing the Same, CA1209749 A, August 12, 1986. 
[6] M. C. Saha et al., Effect of density, microstructure, and strain rate on compression behavior of polymeric foams, Materials Science and Engineering: A 406(1-2) (2005), 328-336.

DOI: https://doi.org/10.1016/j.msea.2005.07.006

[7] M. L. Auad et al., Flammability properties and mechanical performance of epoxy modified phenolic foams, Journal of Applied Polymer Science 104(3) (2007), 1399-1407.

DOI: https://doi.org/10.1002/app.24405

[8] B. Del Saz-Orozco et al., Effects of formulation variables on density, compressive mechanical properties and morphology of wood flour-reinforced phenolic foams, Composites Part B: Engineering 56 (2014), 546-552.

DOI: https://doi.org/10.1016/j.compositesb.2013.08.078

[9] A. Desai et al., Mechanical behavior of hybrid composite phenolic foam, Journal of Cellular Plastics 44(1) (2008), 15-36.

DOI: https://doi.org/10.1177/0021955X07078021

[10] H. Shen, A. J. Lavoie and S. R. Nutt, Enhanced peel resistance of fiber reinforced phenolic foams, Composites Part A: Applied Science and Manufacturing 34(10) (2003), 941-948.

DOI: https://doi.org/10.1016/S1359-835X(03)00210-0

[11] H. Shen and S. Nutt, Mechanical characterization of short fiber reinforced phenolic foam, Composites Part A: Applied Science and Manufacturing 34(9) (2003), 899-906.

DOI: https://doi.org/10.1016/S1359-835X(03)00136-2

[12] Datasheet of Last-A-Foam 3700, Series - General Plastics, Accessed 31 May 2018.

https://www.nrc.gov/docs/ML0504/ML050410066.pdf

[13] B. Del Saz-Orozco et al., Mechanical, thermal and morphological characterization of cellulose fiber-reinforced phenolic foams, Composites Part B: Engineering 75 (2015), 367-372.

DOI: https://doi.org/10.1016/j.compositesb.2015.01.049

[14] B. Del Saz-Orozco et al., Lignin particle- and wood flour-reinforced phenolic foams: Friability, thermal stability and effect of hygrothermal aging on mechanical properties and morphology, Composites Part B: Engineering 80 (2015), 154-161.

DOI: https://doi.org/10.1016/j.compositesb.2015.05.043

[15] V. K. Rangari et al., Cloisite clay-infused phenolic foam nanocomposites, Journal of Applied Polymer Science 103(1) (2007), 308-314.

DOI: https://doi.org/10.1002/app.25287

[16] Q. Xu et al., Preparation of high-strength microporous phenolic open-cell foams with physical foaming method, High Performance Polymers 27(7) (2015), 852-867.

DOI: https://doi.org/10.1177/0954008314564197 
[17] F. Saint-Michel et al., Mechanical properties of high density polyurethane foams: I, Effect of the density, Composites Science and Technology 66(15) (2006), 2700-2708.

DOI: https://doi.org/10.1016/j.compscitech.2006.03.009

[18] Y. Chen, R. Das and M. Battley, Effects of cell size and cell wall thickness variations on the stiffness of closed-cell foams, International Journal of Solids and Structures 52 (2015), 150-164.

DOI: https://doi.org/10.1016/j.ijsolstr.2014.09.022

[19] Z. G. Xu et al., Effects of cell size on quasi-static compressive properties of Mg alloy foams, Materials \& Design 34 (2012), 40-44.

DOI: https://doi.org/10.1016/j.matdes.2011.07.066

[20] C. Gaétane, Elaboration et Caractérisation de Matériaux Polymères Poreux Modèles à Base d'Émulsions Contrôlées, in, Université Sciences et Technologies - Bordeaux I, 2001.

[21] G. K. Rickle and K. R. Denslow, The effect of water on phenolic foam cell structure, Journal of Cellular Plastics 24(1) (1988), 70-78.

DOI: https://doi.org/10.1177/0021955X8802400104

[22] R. Gosselin and D. Rodrigue, Cell morphology analysis of high density polymer foams, Polymer Testing 24(8) (2005), 1027-1035.

DOI: https://doi.org/10.1016/j.polymertesting.2005.07.005

[23] W. E. Warren and A. M. Kraynik, The linear elastic properties of open-cell foams, Journal of Applied Mechanics 55(2) (1988), 341-346.

DOI: https://doi.org/10.1115/1.3173680

[24] C. Yang, Z. H. Zhuang and Z. G. Yang, Pulverized polyurethane foam particles reinforced rigid polyurethane foam and phenolic foam, Journal of Applied Polymer Science 131(1) (2014), 39734.

DOI: https://doi.org/10.1002/app.39734

[25] H. Yu, L. Wang and G. Gai, Performance of modified aramid fiber reinforced phenolic foam, Advanced Materials Research 557-559 (2012), 258-261.

DOI: https://doi.org/10.4028/www.scientific.net/AMR.557-559.258

[26] J. J. Yuan, Y. B. Zhang and Z. Z. Wang, Phenolic foams toughened with crosslinked poly (n-butyl acrylate)/silica core-shell nanocomposite particles, Journal of Applied Polymer Science 132(40) (2015), 42590.

DOI: https://doi.org/10.1002/app.42590

[27] L. Li et al., Preparation and characterization of phenolic foam modified by Nitrile butadiene rubber powder, Applied Mechanics and Materials 204-208 (2012), 4137-4142.

DOI: https://doi.org/10.4028/www.scientific.net/AMM.204-208.4137 
[28] Y. Ma et al., Effect of zinc oxide on properties of phenolic foams/halogen-free flame retardant system, Journal of Applied Polymer Science 132(44) (2015), 42730.

DOI: https://doi.org/10.1002/app.42730

[29] Q. Li et al., Effect of nano-titanium nitride on thermal insulating and flameretardant performances of phenolic foam, Journal of Applied Polymer Science 133(32) (2016), 43765.

DOI: https://doi.org/10.1002/app.43765

[30] X. Li et al., One-step in situ synthesis of a novel $\alpha$-zirconium phosphate/graphene oxide hybrid and its application in phenolic foam with enhanced mechanical strength, flame retardancy and thermal stability, RSC Advances 6(78) (2016), 74903-74912.

\section{DOI: https://doi.org/10.1039/C6RA12208F}

[31] Y. F. Yang and J. M. He, Mechanical characterization of phenolic foams modified by short glass fibers and polyurethane prepolymer, Polymer Composites 36(9) (2015), 1584-1589.

$$
\text { DOI: https://doi.org/10.1002/pc.23066 }
$$

[32] H. Y. Ding et al., Preparation and properties of a novel flame retardant polyurethane quasi-prepolymer for toughening phenolic foam, Journal of Applied Polymer Science 132(35) (2015), 42424.

DOI: https://doi.org/10.1002/app.42424

[33] J. T. Zhou et al., Fabrication and mechanical properties of phenolic foam reinforced with graphene oxide, Polymer Composites 35(3) (2014), 581-586.

DOI: https://doi.org/10.1002/pc.22698 